CrossMark \& click for updates

Cite this: J. Mater. Chem. C, 2016, 4, 11269

Received 26th October 2016, Accepted 14th November 2016

DOI: $10.1039 / c 6 t c 04647 a$

www.rsc.org/MaterialsC

\section{Progression towards high efficiency perovskite solar cells via optimisation of the front electrode and blocking layer}

\author{
Heather M. Yates, ${ }^{\star a}$ Mohammad Afzaal, ${ }^{a}$ Arnaud Walter, ${ }^{b}$ John L. Hodgkinson, ${ }^{a}$ \\ Soo-Jin Moon, ${ }^{b}$ Davide Sacchetto, ${ }^{b}$ Matthias Bräuninger, ${ }^{C}$ Björn Niesen, ${ }^{c}$ \\ Sylvain Nicolay, ${ }^{b}$ Melissa McCarthy, ${ }^{d}$ Martyn E. Pemble, ${ }^{d}$ Ian M. Povey ${ }^{d}$ and \\ Christophe Ballif ${ }^{\mathrm{b}}$
}

\section{Introduction}

In recent years there has been an intensification of interest over solid-state organic-inorganic hybrid perovskite solar cells. Early work started with Mitzi et al. ${ }^{1}$ with tin based iodides, then continued with progressive changes from tin to lead halides ${ }^{2}$ and liquid to solid electrolytes in particularly that of spiro$\mathrm{OMeTAD}^{3,4}$ which dramatically improved cell efficiency from round $3.8 \%$ to $9.7-10.9 \%$. In addition there have been changes to the type/or mix of halides, ${ }^{5,6}$ organic cations ${ }^{7}$ and more recently use of 'triple cations' with the addition of cesium to increase the durability of the films during cell processing. ${ }^{8}$ These gradual changes have led to present day efficiencies in excess of $22 \% .{ }^{9}$

The basic and most common types of cells are the mesoscopic and planar structures, which are illustrated schematically in Fig. 1. In the mesoscopic form the metal halide perovskite

\footnotetext{
${ }^{a}$ Materials and Physics Research Centre, University of Salford, Cockcroft Building, Manchester, M5 4WT, UK. E-mail: H.M.Yates@salford.ac.uk

${ }^{b}$ Centre Suisse d'Electronique et de Microtechnique (CSEM), PV-Center, Jaquet-Droz 1, 2002 Neuchâtel, Switzerland

${ }^{c}$ Ecole Polytechnique Fédérale de Lausanne (EPFL), Institute of Microengineering (IMT), Photovoltaics and Thin-Film Electronics Laboratory,

Rue de la Maladière 71b, 2002 Neuchâtel, Switzerland

${ }^{d}$ Tyndall National Institute, Cork, Ireland
}

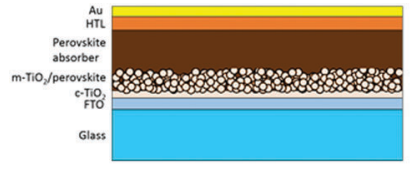

(a)

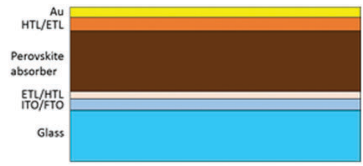

(b)
Fig. 1 Schematics of a perovskite based cell (a) mesoscopic, (b) planar.

absorber is infiltrated through a charge-conducting mesoporous scaffold, often $\mathrm{TiO}_{2}$ (titanium dioxide). The photogenerated electrons from the perovskite layer are transferred to the mesoporous sensitized layer through which they are transported to the electrode and extracted into the circuit. This active layer is contacted with an n-type material for electron extraction (electron transport layer - ETL) and a p-type material for hole extraction (hole transport layer - HTL). The ETL layer also acts as a blocking layer (BL) to block recombination between the electrons in the front electrode and the holes in the perovskite. In contrast the planar structure does not have a scaffold so after light absorption both charge generation as well as charge extraction occurs in the perovskite layer. Both types of carriers are transported through the perovskite to their respective contacts. Usually a transparent conducting oxide (TCO) often 
F-doped tin oxide or indium tin oxide is used for the front electrode contact and gold for the back contact.

The majority of literature published on this subject concentrates on the perovskite layer itself, with studies on its deposition, ${ }^{10-12}$ composition, structure, ${ }^{13}$ and the stability ${ }^{14}$ and how it effects the cell characteristics. ${ }^{15,16}$ However, there is much less discussion on the effects of other layers such as the BL (ETL) and TCO electrode. As already stated the BL acts to block recombination between the TCO electrons and the perovskite holes, while at the same time needs to provide efficient electron extraction from the perovskite to TCO. A thicker BL would decrease the charge recombination between the perovskite holes and TCO electrons, but would also reduce the electron flow to the TCO due to a higher series resistance in the cell, so a balance of conditions is required. A detailed studied by Choi et al. ${ }^{17}$ looked at the deposition method and resulting properties of BLs for producing planar solar cells emphasizing the importance of well-defined, defect free morphologies with uniform thickness. Most cells reported use $\mathrm{TiO}_{2}$, although alternatives materials have been tested such as $\mathrm{SnO}_{2},{ }^{18}$ composite graphene/ $\mathrm{TiO}_{2}{ }^{19}$ and $\mathrm{ZnO}^{20}$

The role of the TCO characteristics has had very limited discussion, with researchers commonly using a commercially supplied standard material. The most utilised TCO is F-doped $\mathrm{SnO}_{2}$ (FTO) such as TEC 7, TEC 8 (NSG), or TCO22-15 (Solaronix). Previous work by us ${ }^{21}$ concentrated on FTOs optimised for use in thin film silicon (Si) PV cells, which requires high optical transparency, low resistivity and high surface roughness. The latter to increase internal light trapping to improve the efficiency of light use by the absorbing layers as Si (especially a-Si) has a low absorption efficiency. For perovskite cells the first two properties still apply, but as perovskite already has excellent absorption coefficients ${ }^{22}$ the overriding factor is to achieve a suitable uniform surface to enable good adhesion and no pin holes through the $\mathrm{BL}$ and hence direct perovskite contact. The FTO morphology directs that of the BL and hence that of the perovskite so is an important factor towards cell efficiency. A too rough a surface tends to lead to FTO spikes or pin holes into the perovskite and hence fast electron/hole recombination. A non-uniform, rough surface also can lead to lower adhesion between the various layers, with the knock-on effect of poorer films and much lower cell efficiencies. Another important and related factor is the wettability of the $\mathrm{TiO}_{2-x}$ surface to the perovskite precursor solution and hence its solid surface coverage and crystallinity. It has previously been shown that use of a rougher $\mathrm{TiO}_{2-x}$ surface gave better wettability, hence a lower energy barrier to the heterogeneous nucleation on the liquid/solid interface. ${ }^{23}$ The perovskite layer improvement (coverage, adhesion and crystallinity) in turn led to improved cell properties. Hence, there is an advantage in starting with a relatively rough TCO surface which can lead to the formation of a similar morphology for the BL.

In this paper, we concentrate on studying the effects of the FTO electrode and $\mathrm{TiO}_{2-x}$ blocking layer. In addition some changes to the perovskite precursor composition were considered on the overall properties of the PV cell. From this we aim to combine the optimised properties leading to improved cell efficiencies. For the FTO films the effects of roughness, dopant level and resistivity on the cell characteristics will be discussed. We show that the combination of FTO properties required to give low resistivity, high optical transmission and relatively uniform surfaces will aid in the improvement of PV efficiency.

For the BL, the effects of different deposition methods, namely those of atomic layer deposition (ALD), spin and sputter coating will be studied to show the importance of technique chosen, layer thickness and the need to produce dense, pin hole free conformal films. In addition, optimisation of the spin coated perovskite via precursor/solvent changes will be studied.

\section{Experimental}

\section{Thin films}

Fluorine doped tin oxide. Thin films were deposited by APCVD at a deposition temperature of $600{ }^{\circ} \mathrm{C}$ using monobutyl tin trichloride (MBTC) with $0.2,0.6$ or $1.0 \mathrm{M}$ aqueous trifluoroacetic acid (TFAA), delivered with a Sn precursor to $\mathrm{H}_{2} \mathrm{O}$ molar ratio of [1]:[5] or [1]:[30]. Precursors were vapourised using either a bubbler (MBTC at $125{ }^{\circ} \mathrm{C}, 0.7 \mathrm{~L} \mathrm{~min}^{-1}$ carrier gas) or flash evaporation (TFAA/water mix, $0.6 \mathrm{~L} \mathrm{~min}^{-1}$ carrier gas). $\mathrm{N}_{2}$ was used as the carrier gas. The process flow was set to $7 \mathrm{~L} \mathrm{~min}{ }^{-1}$ with oxygen $\left(1.5 \mathrm{~L} \mathrm{~min}^{-1}\right)$ giving a total flow of $\sim 9.8 \mathrm{~L} \mathrm{~min}^{-1}$. Deposition was on $1 \mathrm{~mm}$ thick borosilicate (Corning Eagle 2000) glass. The heated substrate is translated, on an automated stage, beneath a static, non-contact CVD head (i.e. gas distributor) in an extracted, open atmosphere, enclosure. This allows the deposition of extended area films with high uniformity over $100 \mathrm{~mm}$ width $( \pm 2 \%)$ and the length is only limited by the translation table size. For these experiments, samples of $100 \mathrm{~mm} \times 100 \mathrm{~mm}$ were provided for cell fabrication. The film thickness was varied by changing the number of passes under the coating head. For each type of deposition parameter several samples were prepared. This then enabled the fabrication of a greater number of cells and hence increased confidence in the resulting data.

Titania blocking layers. Spin coated blocking layers were prepared by using a precursor solution, $0.15 \mathrm{M}$ titanium diisopropoxide dis(acetylacetonate) (Sigma-Aldrich, $75 \mathrm{wt} \%$ in isopropanol) in 1-butanol (Sigma-Aldrich, 99.8\%). The precursor solution was spin-coated on a FTO glass substrate at $1000 \mathrm{rpm}$ for $10 \mathrm{~s}$ and $2000 \mathrm{rpm}$ for $20 \mathrm{~s}$, which was followed by sintering at $450{ }^{\circ} \mathrm{C}$ for 30 minutes.

Thin-films of $\mathrm{TiO}_{2-x}$ with $23 \mathrm{~nm}$ thickness have been deposited by RF sputtering at $60^{\circ} \mathrm{C}$. The stoichiometry of the thin films could be controlled by adjusting the $\mathrm{Ar}$ and $\mathrm{Ar}: \mathrm{O}_{2}$ flows in the sputtering chamber. Thus the electrical conductivity and the transparency of the $\mathrm{TiO}_{2-x}$ films could be tuned in order to get the optimal optoelectronic properties for the solar cells.

Thin films with a range of thicknesses (10-30 nm) have been deposited by employing a Cambridge Nanotech-Ultratech F200 ALD system. Tetrakis dimethylamino titanium (TDMAT) and $\mathrm{H}_{2} \mathrm{O}$ in an argon carrier flow were employed as the metal precursor and oxygen source, respectively. The deposition 
temperature was $200{ }^{\circ} \mathrm{C}$, leading to a deposition rate of $0.5 \AA$ per cycle.

\section{Cell fabrication}

The mesoporous $\mathrm{TiO}_{2}\left(\mathrm{~m}-\mathrm{TiO}_{2}\right)$ layer was deposited on the $\mathrm{TiO}_{2-x}$ blocking layers/FTO coated substrates by spin coating $\mathrm{TiO}_{2}$ paste (Dyesol 18NRT) diluted in isopropanol $(1 \mathrm{~g}$ in $10 \mathrm{ml}$ ) at $2000 \mathrm{rpm}$ for $30 \mathrm{~s}$ and annealed at $500{ }^{\circ} \mathrm{C}$ for 30 minutes. Three different perovskite recipes were used for the optimization of the perovskite layer. The same $\mathrm{CH}_{3} \mathrm{NH}_{3} \mathrm{PbI}_{3}$ precursor solution was used for recipes 1 and 2 but the dripping amount of toluene was increased from $60 \mu \mathrm{l}$ to $1 \mathrm{ml}$ in recipe $2.1 .2 \mathrm{M}$ $\mathrm{PbI}_{2}$ (TCI) and $\mathrm{CH}_{3} \mathrm{NH}_{3} \mathrm{I}$ (Dyesol) were dissolved in a mixture of $\gamma$-butyrolactone (GBL) and dimethyl sulfoxide (DMSO) $(7: 3$ volume ratios) at $70{ }^{\circ} \mathrm{C} . \mathrm{A} \mathrm{CH}_{3} \mathrm{NH}_{3} \mathrm{PbI}_{3}$ precursor solution was then spin coated on the $\mathrm{m}-\mathrm{TiO}_{2}$ substrate at $1000 \mathrm{rpm}$ and $5000 \mathrm{rpm}$ for $10 \mathrm{~s}$ and $30 \mathrm{~s}$, respectively. During the 2nd step of spin coating, toluene was dropped on the substrate and the perovskite layer was dried at $100{ }^{\circ} \mathrm{C}$ for $10 \mathrm{~min}$. In recipe 3 , $461 \mathrm{mg}$ of $\mathrm{PbI}_{2}, 159 \mathrm{mg}$ of $\mathrm{CH}_{3} \mathrm{NH}_{3} \mathrm{I}$, and $78 \mathrm{mg}$ of DMSO (molar ratio $1: 1: 1$ ) were mixed in $600 \mathrm{mg}$ of dimethylformamide (DMF) solution at room temperature with stirring for $1 \mathrm{~h}$ in order to prepare the $\mathrm{CH}_{3} \mathrm{NH}_{3} \mathrm{PbI}_{3}$ precursor solution. The precursor solution was spin coated on the $\mathrm{m}-\mathrm{TiO}_{2}$ substrate in a two-stage sequence $(1000 \mathrm{rpm}$ for $10 \mathrm{~s}$ followed by $5000 \mathrm{rpm}$ for $45 \mathrm{~s}$ ) and $0.75 \mathrm{ml}$ of diethyl ether was dripped onto the substrate $12 \mathrm{~s}$ before the end of the procedure. The substrate was then heated at $50{ }^{\circ} \mathrm{C}$ for $2 \mathrm{~min}$ and $100{ }^{\circ} \mathrm{C}$ for 10 minutes. ${ }^{24}$ Spiro-OMeTAD solution was prepared by dissolving $72.3 \mathrm{mg}$ spiro-OMeTAD (Merck), $28.8 \mu \mathrm{l}$ 4-tert-butylpyridine (Sigma-Aldrich), $17.5 \mu \mathrm{l}$ of a stock solution of $520 \mathrm{mg} \mathrm{m}^{-1}$ lithium bis(trifluoromethylsulfonyl)imide (Sigma-Aldrich) in $1 \mathrm{ml}$ chlorobenzene and this was spin coated on top of the perovskite layer at $4000 \mathrm{rpm}$ for 30 seconds. The cells were then finished with the evaporation of a $100 \mathrm{~nm}$ thick gold electrode.

\section{Characterisation}

Thin films. The morphology and surface roughness of the samples were obtained by atomic force microscopy (NanoScope IIIa, Digital Inst. Ltd). Images were also obtained via scanning electron microscopy (Philips ESEM FEG XL30). The film thickness for the FTOs was determined by etching the films with $\mathrm{HCl} / \mathrm{Zn}$ metal to give a step edge, followed by surface profiling on a Dektak 3ST. The resistivity of the films was measured using a Jandel Universal four point probe. Hall effect measurements were performed on the TCO films to determine the carrier concentration and the electron mobility with a lab built system using an electromagnetic with a pole separation of $12.5 \mathrm{~mm}$ and current of $1.1 \mathrm{~A}$ to give a magnetic flux density of $0.66 \mathrm{~T}$. A lab built spectrometer consisting of a $75 \mathrm{~W}$ xenon lamp and four broadband filters centring on four wavelengths $(800,650,531$, and $450 \mathrm{~nm})$ was used to measure optical properties. A silica sample was used to calibrate the throughput of the integrating sphere. For more detailed optical measurements spectrophotometry (UV-Vis-NIR) was performed with a Perkin-Elmer Lambda 900 spectrophotometer equipped with an integrating sphere. Dark conductivity measurements of the $\mathrm{TiO}_{2-x}$ samples were performed under 1 mbar $\mathrm{N}_{2}$ atmosphere and in the dark. During the measurement, the temperature is ramped up from room temperature to $180{ }^{\circ} \mathrm{C}$ with a rate of $10^{\circ} \mathrm{C} \mathrm{min}{ }^{-1}$ then the sample is slowly cooled down at a rate of $1{ }^{\circ} \mathrm{C} \min ^{-1}$. The conductivity was taken during the cool down phase for a more precise temperature measurement.

Cell characterisation. All cells were characterized under a two-lamp class AAA WACOM sun simulator with an AM 1.5G irradiance spectrum at $1000 \mathrm{~W} \mathrm{~m}^{-2}$. The cell area was defined using a metal mask. The $I-V$ characteristics of the cells were obtained under both reverse (from $V_{\mathrm{oc}}$ to $J_{\mathrm{sc}}$ ) and forward (from $J_{\mathrm{sc}}$ to $V_{\mathrm{oc}}$ ) bias. A maximum power point (MPP) tracking was usually performed to extract the stabilized power output. External quantum efficiency (EQE) spectra were acquired on a custom-made spectral response setup equipped with a xenon lamp, a grating monochromator and lock-in amplifiers.

\section{Results and discussion}

Thin films of $\mathrm{SnO}_{2}$ :F were deposited by APCVD as previously described by $\mathrm{us}^{25}$ with changes to the $\mathrm{F}$ dopant level, tin precursor to $\mathrm{H}_{2} \mathrm{O}$ molar ratio and thickness via the number of coater head passes (Table 1).

\section{Initial trials with FTO sets A, B and C}

For preliminary work, two types of FTO were deposited with differing surface roughness (RMS $33 \mathrm{~nm}, 22 \mathrm{~nm}$ ), although they had similar sheet resistance $\left(\sim 20 \mathrm{Ohm} \mathrm{sq}^{-1}\right)$. The reduction in roughness while keeping the resistance constant was achieved by reducing film thickness and increasing the $\mathrm{H}_{2} \mathrm{O}$ :MBTC precursor ratio. In APCVD (assuming only the time of deposition is changed) it is expected that the film gets rougher as the film thickness increases. The FTO growth is columnar ${ }^{26}$ and polycrystalline. ${ }^{27}$ As different crystallographic orientations grow at a different rate the differences are accentuated as the film gets thicker, so increasing the surface roughness. A thinner sample would exhibit increased sheet resistance, unless the dopant levels were increased to reduce bulk resistivity which may risk performance loss due to increased free carrier absorption. The first batch of samples (set A) sent for the solar cell fabrication were produced using a $5: 1 \mathrm{H}_{2} \mathrm{O}$ : MBTC precursor ratio which

Table 1 Deposition conditions and electrical properties for FTO sets A, B and $\mathrm{C}$

\begin{tabular}{|c|c|c|c|c|c|c|c|c|}
\hline Set & $\mathrm{H}_{2} \mathrm{O}: \mathrm{MBTC}$ & $\begin{array}{l}\text { TFAA } \\
\text { (M) }\end{array}$ & $\begin{array}{l}d \\
(\mathrm{~nm})\end{array}$ & $\begin{array}{l}\text { RMS } \\
\text { (nm) }\end{array}$ & $\begin{array}{l}R_{\mathrm{S}}(\Omega \\
\left.\mathrm{sq}^{-1}\right)\end{array}$ & $\begin{array}{l}p / \times 10^{-4} \\
\left(\Omega \mathrm{cm}^{-1}\right)\end{array}$ & $\begin{array}{l}\mu\left(\mathrm{cm}^{2}\right. \\
\left.\mathrm{V}^{-1} \mathrm{~s}^{-1}\right)\end{array}$ & $\begin{array}{l}N / \times 10^{20} \\
\left(\mathrm{~cm}^{-3}\right)\end{array}$ \\
\hline Ref. & $\mathrm{N} / \mathrm{A}$ & N/A & 400 & 14 & 13 & 5.2 & 28 & 4.2 \\
\hline A & $5: 1$ & 0.2 & 1042 & 33 & 19 & 20 & 22 & 2.4 \\
\hline B & $30: 1$ & 0.2 & 550 & 22 & 18 & 10 & 22 & 3.4 \\
\hline C1 & $30: 1$ & 0.6 & 365 & 16 & 21 & 7.6 & 28 & 2.7 \\
\hline $\mathrm{C} 2$ & $30: 1$ & 0.6 & 483 & 20 & 14 & 6.7 & 31 & 3.4 \\
\hline C3 & $30: 1$ & 1 & 410 & 20 & 14 & 5.6 & 23 & 4 \\
\hline $\mathrm{C} 4$ & $30: 1$ & 1 & 326 & 17 & 23 & 7.6 & 25 & 3.7 \\
\hline
\end{tabular}

$d$ : average film thickness, AFM - root mean squared (RMS) roughness, $R_{\mathrm{s}}$ : sheet resistance, $p$ : resistivity, $\mu$ : mobility, $N$ : carrier concentration. 
Table 2 Cell data for set A, B and C

\begin{tabular}{|c|c|c|c|c|c|c|c|c|}
\hline & Sample ID & $\begin{array}{l}\text { Method of blocking } \\
\text { layer (nm) }\end{array}$ & $\begin{array}{l}\text { PCE } \\
(\%)\end{array}$ & $\begin{array}{l}V_{\mathrm{oc}} \\
(\mathrm{mV})\end{array}$ & $\begin{array}{l}J_{\mathrm{sc}} \\
(\mathrm{mA} \mathrm{cm}\end{array}$ & $\begin{array}{l}\text { FF } \\
(\%)\end{array}$ & $\begin{array}{l}R_{\mathrm{sc}} \\
\left(\Omega \mathrm{cm}^{2}\right)\end{array}$ & $\begin{array}{l}R_{\mathrm{oc}} \\
\left(\Omega \mathrm{cm}^{2}\right)\end{array}$ \\
\hline \multirow[t]{6}{*}{ Original recipe (set $\mathrm{A}$ and $\mathrm{B}$ ) } & Reference & Spin coated & 8.436 & 887 & 16.06 & 59.2 & 925 & 7.67 \\
\hline & A1 & Spin coated & 9.858 & 911.8 & 17.4 & 62.12 & 1924 & 7.711 \\
\hline & & ALD (10) & 10.06 & 921.6 & 18.38 & 59.42 & 6662 & 9.943 \\
\hline & & ALD (20) & 10.37 & 946.5 & 18.44 & 59.4 & 3604 & 11.83 \\
\hline & & ALD (30) & 6.156 & 858.7 & 17.64 & 40.65 & 695.2 & 29.74 \\
\hline & B1 & Spin coated (10-15) & 9.776 & 878.3 & 17.58 & 63.31 & 786.1 & 7.139 \\
\hline \multirow[t]{4}{*}{ New recipe (set $A$ and $B$ ) } & Reference & Spin coated & 13.35 & 1040 & 19.92 & 64.43 & 1175 & 3.783 \\
\hline & $\mathrm{A} 2$ & Spin coated & 13.37 & 1023 & 18.96 & 68.9 & 1043 & 5.473 \\
\hline & & Spin coated & 14.68 & 1029 & 20.29 & 70.34 & 1672 & 5.464 \\
\hline & B2 & Spin coated & 9.276 & 786.9 & 20.4 & 57.78 & 2786 & 8.112 \\
\hline \multirow[t]{9}{*}{ New recipe (set C) } & Reference & ALD & 15 & 1036 & 18.81 & 76.98 & 2874 & 5.441 \\
\hline & Reference & ALD & 14.84 & 1043 & 19.19 & 74.18 & 2860 & 5.729 \\
\hline & C1 & ALD & 4.569 & 761 & 18.71 & 32.09 & 72.07 & 17.39 \\
\hline & $\mathrm{C} 2$ & ALD & 14.33 & 1043 & 19.27 & 71.33 & 1826 & 4.282 \\
\hline & & ALD & 14.68 & 1047 & 19.86 & 70.58 & 2203 & 5.153 \\
\hline & C3 & ALD & 14.7 & 1057 & 19.77 & 70.34 & 1640 & 4.614 \\
\hline & & ALD & 11.34 & 10.2 & 19.4 & 56.61 & 447.7 & 8.169 \\
\hline & $\mathrm{C} 4$ & ALD & 13.29 & 1075 & 19.5 & 63.4 & 898.7 & 7.076 \\
\hline & & ALD & 14.66 & 1049 & 19.37 & 72.14 & 3330 & 7.565 \\
\hline \multirow{5}{*}{$\begin{array}{l}\text { New recipe (set C; } \\
\text { re-measured after } 3 \text { days) }\end{array}$} & Reference & ALD & 15.18 & 1028 & 20.2 & 73.09 & 2106 & 5.015 \\
\hline & Reference & ALD & 14.62 & 1023 & 20.35 & 70.18 & 2550 & 4.915 \\
\hline & $\mathrm{C} 2$ & ALD & 15.4 & 1031 & 20.54 & 72.69 & 1830 & 4.927 \\
\hline & $\mathrm{C} 3$ & ALD & 15.2 & 1049 & 20.25 & 71.67 & 4049 & 6.088 \\
\hline & $\mathrm{C} 4$ & ALD & 14.13 & 1055 & 20.71 & 64.64 & 2047 & 9.399 \\
\hline
\end{tabular}

had an thickness of $1042 \mathrm{~nm}$. In contrast, the second batch of samples (set B) produced using a 30:1 $\mathrm{H}_{2} \mathrm{O}:$ MBTC ratio had a thickness of $550 \mathrm{~nm}$. A third sample was deposited at the higher $\mathrm{H}_{2} \mathrm{O}$ : MBTC precursor ratio, but had a similar thickness to set A. This had a similar roughness to set A but a much lower sheet resistance. For the three FTO films discussed in this section it can be seen that if only the film thickness is increased $\left(\mathrm{H}_{2} \mathrm{O}\right.$ : MBTC fixed), then roughness increases. However, if only the precursor ratio is increased (thickness fixed), then the roughness does not change. Therefore the roughness of the film depends on the film thickness not the precursor ratio. However, at the higher ratio the slightly increased doping level (as the TFAA is transported with the water) kept the resistance down.

To put our results into perspective the samples were compared to a high quality commercially available FTO thin film - Solaronix TCO22-15. This has a $400 \mathrm{~nm}$ thick FTO layer with an RMS roughness of $14 \mathrm{~nm}$. The electrical properties, as measured on our instrumentation, gave a sheet resistance of $13 \Omega \mathrm{sq}^{-1}$, carrier concentration $4.2 \times 10^{20} \mathrm{~cm}^{-3}$ and mobility $28 \mathrm{~cm}^{2} \mathrm{~V}^{-1} \mathrm{~s}^{-1}$. This was both thinner, with much lower roughness than our APCVD FTO, with lower sheet resistance and higher mobility. The electrical properties of this commercial product are in line with its much higher carrier concentration. Optical scattering (haze) measurements confirmed the variation in sample roughness showing an increase in haze with surface roughness. Reference cells were fabricated on the commercial FTO concurrent to production of those on our TCO samples. This is particularly important as it reduces the possibilities of small variations due to deposition equipment and/or operators.
Perovskite PV cells were fabricated on APCVD and commercial FTO with spin coated $\mathrm{TiO}_{2-x}$ blocking layers, followed (as described in experimental section) by a mesoporous $\mathrm{TiO}_{2}$ scaffold, perovskite, spiro-OMeTAD and Au contact. Interestingly, both sets of FTO CVD derived cells performed well, exceeding the efficiency achieved with use of the commercial TCO, used as a reference, by over $1 \%$ abs. in each case (Table 2), representing an improvement in the order of $10 \%$. This is particularly noticeable as the commercial TCO reference despite the lower sheet resistance and higher carrier mobility, which would be expected to give the cell a higher efficiency in removing the generated current, does not perform as well overall. However, it does have higher carrier concentration than the other FTO samples. This will decrease the optical transmission via free carrier absorption and hence reduce the amount of light reaching the absorber parts of the cell. The relationship between carrier concentration and transmission has been seen previously for TCO ZnO electrodes in thin film silicon solar cells. ${ }^{28}$ In addition the reference cell has a lower short circuit current density $\left(J_{\mathrm{sc}}\right)$, which in previous cell literature has been related to lower internal light scattering due to the TCO increased smoothness. ${ }^{25,29}$ The higher PCE values for set A and B cells suggested that while using a mesoporous scaffold layer the level of FTO roughness is not an issue. Previously it has been shown that addition of a scaffold layer tends to reduce series resistance $\left(R_{\mathrm{oc}}\right)$ and hence increase the fill factor $(\mathrm{FF})$, along with the open circuit voltage $\left(V_{\mathrm{oc}}\right)$ and shunt resistance $\left(R_{\mathrm{sc}}\right) .^{7}$

\section{Choice of BL deposition method - spin coating v ALD}

This encouraging result prompted studies on the choice of method adopted for depositing the blocking layers. Use of ALD 
to accurately deposit $\mathrm{BL}$ at a range of thicknesses $(10,20$ and $30 \mathrm{~nm}$ ) established an optimum thickness of $20 \mathrm{~nm}$, giving a further increase in PV efficiency as shown in Table 2. Too thick a coating gave a reduction in $R_{\mathrm{sc}}$. A comparison of the method used to deposit the BL showed an advantage in using ALD opposed to spin coating with better $V_{\text {oc }}$ and hence device efficiency. This improvement relates to the increased film density, conformal behaviour and better control of thickness uniformity, which for the spin coated samples was between $10 \mathrm{~nm}$ and $15 \mathrm{~nm}$. ALD is a surface controlled, chemically self-limiting technique for depositing thin films. It is well documented for its ability to produce conformal and pin hole free layers with high thickness uniformity. ${ }^{30}$ Using the same ALD process as us, Chen et al. ${ }^{31}$ demonstrated pinhole free, conformal deposition of only $2 \mathrm{~nm}$ $\mathrm{TiO}_{2}$ over $\mathrm{Si}$ layers. Other studies ${ }^{32}$ on the effect of the BL deposition method, this time ALD, spray pyrolysis and sol-gel also concluded that the improved cell efficiency was due to the ALD dense, pin hole free $\mathrm{TiO}_{2}$. However, there was a lower FF for the ALD opposed to spin coated samples, possibly due to increased series resistance from the FTO contact. Increasing the amount of dripped toluene for the perovskite layer deposition led to an increase in the overall cell efficiency for both reference and set A, although set B (smoother, thinner sample) showed a reduced $V_{\mathrm{oc}}$ and $\mathrm{FF}$ and hence no improvement in efficiency, despite the much greater $R_{\mathrm{sc}}$. Use of a greater amount of toluene led to improved perovskite coverage, a denser structure with a more controllable grain structure and higher reproducibility.

A new batch of FTO CVD samples were provided (set C). These were slightly smoother than set B, thinner (to increase percentage transmission) and of much lower resistivity than both sets A and B (Table 1). An increased dopant level was used to achieve this (0.6 or $1.0 \mathrm{M}$ depending on the exact sample). These were tested with the improved perovskite recipe as well as blocking layers by ALD and spin coated methods. In general, ALD coated samples showed improved power conversion efficiency (PCE) and even surpassed commercial TCO values after re-characterising the cells three days later (Table 2). Samples with a spin coated blocking layer predominantly shunted or yielded low PCE values. This is most likely due to some debris present on the FTO surfaces as shown by SEM analysis (not given), which was not fully covered by the thin spin coated BL. This would lead to direct contact between the FTO and the perovskite, and hence the poor quality cells. This may also explain the previously mentioned lower efficiency of FTO set B with $\mathrm{TiO}_{2-x}$ spin coating with the new perovskite recipe. In addition for those samples in set $\mathrm{C}$ which showed excellent cell efficiency an additional FTO cleaning stage was added to anneal the samples for 1 hour at $500{ }^{\circ} \mathrm{C}$, to help remove any organic debris. FTO films treated under these conditions showed no detrimental failings in optical or electrical properties. The increased conformal behaviour of ALD over spin coating would reduce the number of pin holes introduced by large FTO particles or debris which could not be covered by spin coating. In addition the non-conformal spin coating process, as seen previously, ${ }^{17}$ can lead to a smoother top surface and hence a smaller contact area between BL and perovskite. These processes in spin coating gave increased shunting pathways within the cells and hence resulting in lower device performance. A comparison of cell data showed that use of FTO with the same doping level, but different thickness and hence sheet resistance gave marginally improved cell efficiencies for the thicker and hence lower resistance samples. Increasing the doping level beyond 0.6 M made no conclusive improvement in the cell properties of these samples.

\section{Improved FTO with set D}

Based on the previous results a new batch of FTO was deposited, taking additional care and inspection to ensure no debris was incorporated within the films. For this batch (set D) all deposition parameters were fixed $\left(\mathrm{H}_{2} \mathrm{O}\right.$ : MBTC 5:1, 1 M TFAA) except the number of passes of the coating head over the substrate. This provided a set of FTO samples with three different thicknesses; hence sheet resistance and roughness (Table 3). As would be expected the sheet resistance decreases and roughness increases as the film thickness increases. ${ }^{33}$

The carrier mobility of set $\mathrm{D}$ is fractionally greater than that of the reference TCO sample, while the carrier concentration is lower. The increased optical scatter with film thickness confirms the increased surface roughness, as shown in Fig. 2. The reference FTO gave haze values comparable to its thickness and surface roughness i.e. between the APCVD samples with thicknesses of $350 \mathrm{~nm}$ and $523 \mathrm{~nm}$.

As can be seen in Fig. 3 there is a general decreased in transmission and increase in absorptance as the films increase in thickness, particularly at the higher wavelengths. The reference FTO generally lies within the band of optical values, except for a much increased reflectance $>1500 \mathrm{~nm}$.

Table 3 Some physical and electrical properties of set D

\begin{tabular}{llllll}
\hline Set $\mathrm{D}$ & $d(\mathrm{~nm})$ & $\mathrm{RMS}(\mathrm{nm})$ & $R_{\mathrm{s}}\left(\Omega \mathrm{sq}^{-1}\right)$ & $\mu\left(\mathrm{cm}^{2} \mathrm{~V}^{-1} \mathrm{~s}^{-1}\right)$ & $N / \times 10^{20}\left(\mathrm{~cm}^{-3}\right)$ \\
\hline $\mathrm{D} 1$ & 350 & 13 & 20 & 28 & 3.3 \\
$\mathrm{D} 2$ & 523 & 21 & 11 & 31 & 3.8 \\
$\mathrm{D} 3$ & 745 & 25 & 7 & 34 & 3.5
\end{tabular}

$d$ : average film thickness, AFM - root mean squared (RMS) roughness, $R_{\mathrm{S}}$ : sheet resistance, $\mu$ : mobility, $N$ : carrier concentration.

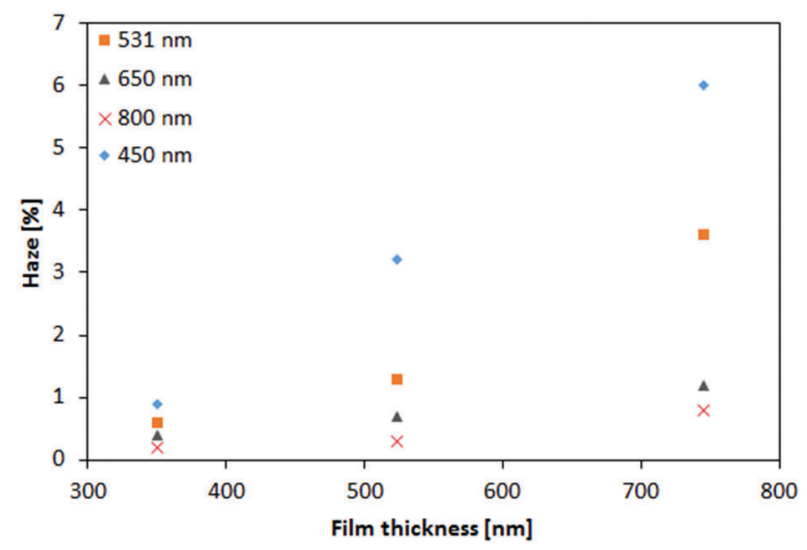

Fig. 2 Optical haze for set D at 4 different wavelengths. 
(a)

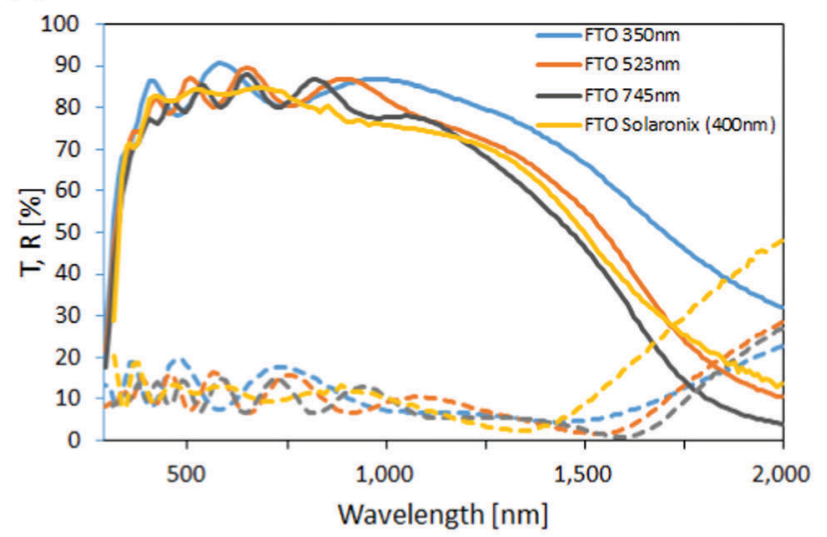

(b)

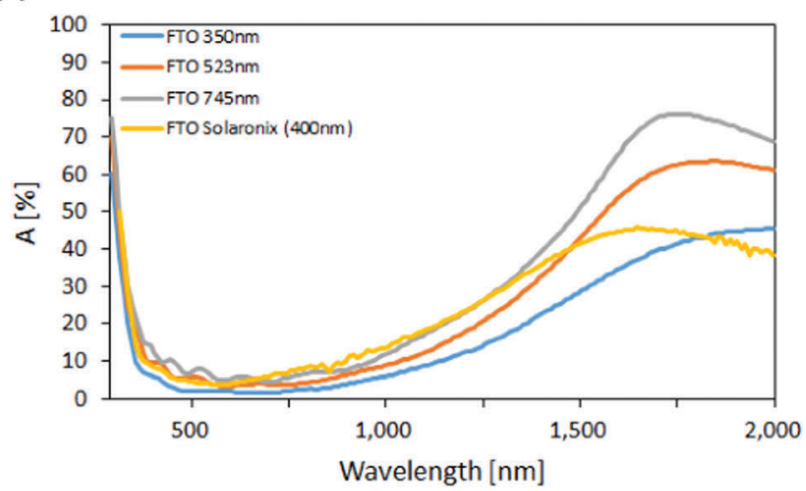

Fig. 3 (a) Transmittance (solid line) and reflectance (dotted line), (b) absorptance.

In all cases the improved quality of the FTO gave cell efficiencies comparable or better than the cells fabricated from the commercial FTO (Table 4). This must arise from a combination of properties as although set $\mathrm{D}$ all has a lower carrier concentration and higher mobility than the reference, it only has lower sheet resistance for two out of three samples. The overriding factor is the higher optical transmittance for our samples. Interestingly, as the FTO increased in thickness there was a corresponding increase in cell FF and decrease in $R_{\mathrm{oc}}$ leading to increased efficiency. This is despite decreased transmission in particularly above $1200 \mathrm{~nm}$ and a possible issue with increased roughness (25 against $13 \mathrm{~nm}$ ). This again confirmed that when using a mesoporous scaffold, FTO roughness is not a problem, given that it is possible to provide a conformal, pin hole free BL. This set of results establishes that the overriding FTO property determining the cell efficiency is its sheet resistance.

\section{Choice of BL deposition method - sputtering v ALD}

As discussed earlier in the paper, deposition of the BL via ALD rather than by spin coating produced more efficient cells. A third technique of magnetron sputtering was used. In both cases $\mathrm{TiO}_{2-x}$ layers were $\sim 20 \mathrm{~nm}$ thick. As shown in Fig. 4a, $\mathrm{TiO}_{2-x}$ by sputtering has an overall dark conductivity ( $\sigma$ dark) which depends on the degree of reduction, with larger electrical conductivity obtained for films deposited without introducing $\mathrm{O}_{2}$ during the sputtering process. At the same time, the Arrhenius plot of the surface conductivity show a typical semi-conductive behaviour, with the conductivity increasing with increasing temperature. This indicates that oxygen vacancies act as a dopant in $\mathrm{TiO}_{2}$, as smaller activation energies are found for $\mathrm{TiO}_{2-x}$ films deposited with more reducing conditions (see Fig. 4b). Such behaviour is ascribed to electrical conduction through mid-gap defect states induced by $\mathrm{Ti}^{3+}$ sites.

Interestingly, the $\mathrm{TiO}_{2-x}$ deposited by ALD shows a very small $E_{\text {a }}$ of only $7 \mathrm{meV}$, which is consistent with a degenerately doped semiconductor. Nonetheless, the absolute value of the $\sigma$ is comparable with the most stoichiometric $\mathrm{TiO}_{2-x}$ film presented in this study, which is ascribed to the higher density of ALD deposited films. In addition, the optical absorptance of

Table 4 Cell data for set $\mathrm{D}$

\begin{tabular}{|c|c|c|c|c|c|c|c|c|}
\hline & Sample ID & Method of blocking layer & PCE $(\%)$ & $V_{\mathrm{oc}}(\mathrm{mV})$ & $J_{\mathrm{sc}}\left(\mathrm{mA} \mathrm{cm}{ }^{-2}\right)$ & $\mathrm{FF}(\%)$ & $R_{\mathrm{sc}}\left(\Omega \mathrm{cm}^{2}\right)$ & $R_{\mathrm{oc}}\left(\Omega \mathrm{cm}^{2}\right)$ \\
\hline & & Sputter & 15.66 & 1069 & 20.00 & 73.26 & 21767 & 7.97 \\
\hline & & ALD & 10.98 & 1044 & 19.15 & 54.91 & 1014 & 30.97 \\
\hline \multirow[t]{2}{*}{350} & D1_1 & Sputter & 13.82 & 1088 & 21.12 & 60.07 & 2047 & 14.02 \\
\hline & D1_2 & Sputter & 13.50 & 1092 & 21.15 & 58.46 & 1027 & 12.75 \\
\hline & D2_2s & Sputter & 15.43 & 1067 & 20.95 & 69.01 & 5472 & 8.87 \\
\hline \multirow[t]{2}{*}{745} & D3_1s & Sputter & 16.66 & 1093 & 20.75 & 73.46 & 24225 & 6.92 \\
\hline & D3_2s & Sputter & 16.46 & 1052 & 21.38 & 73.18 & 11153 & 6.23 \\
\hline \multirow[t]{2}{*}{350} & D1_1a & ALD & 13.96 & 1039 & 22.59 & 59.49 & 2668 & 11.96 \\
\hline & D1_2a & ALD & 13.54 & 1074 & 21.20 & 59.47 & 1380 & 13.52 \\
\hline 745 & D3_1a & ALD & 16.45 & 1073 & 20.76 & 73.85 & 3453 & 5.91 \\
\hline & D3_2a & ALD & 16.33 & 1085 & 20.57 & 73.16 & 23995 & 6.81 \\
\hline
\end{tabular}


(a)
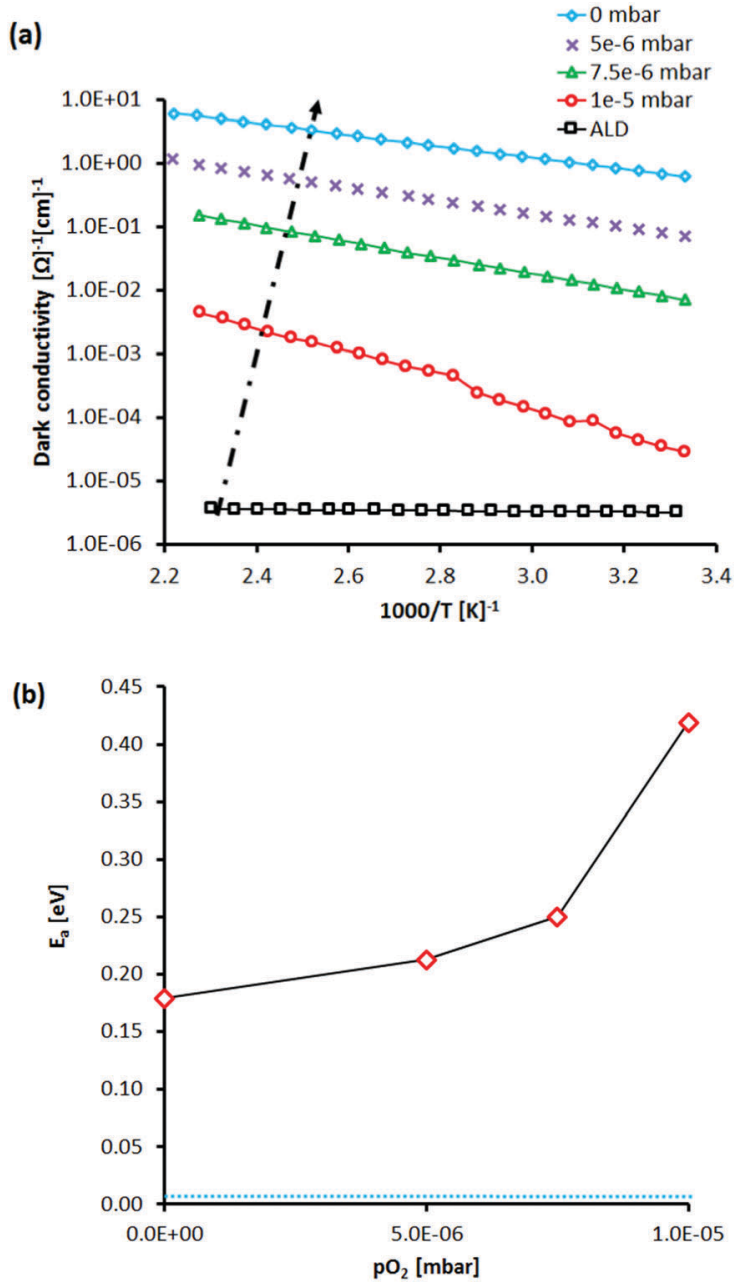

(c)

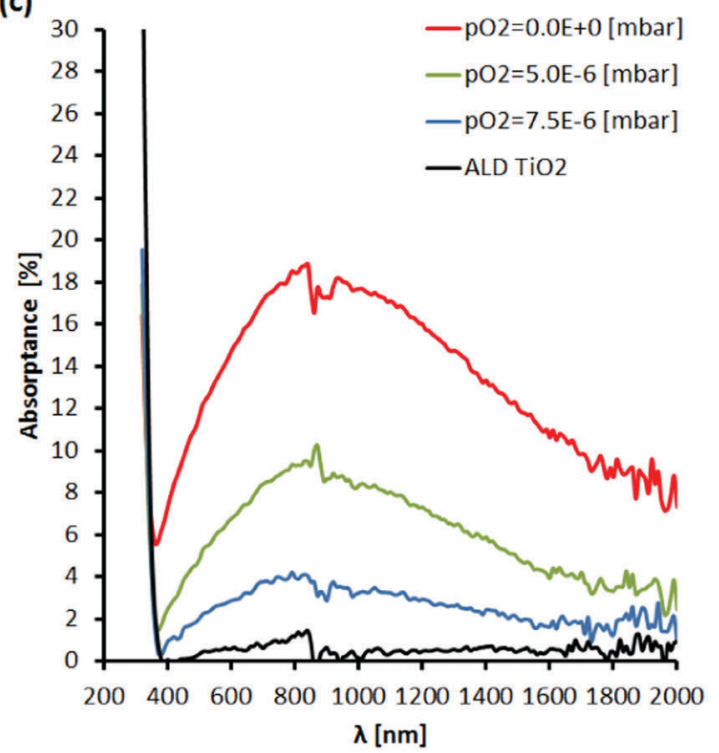

Fig. 4 (a) Arrhenius plot of the surface conductivity of sputtered $\mathrm{TiO}_{2-x}$ and $\mathrm{TiO}_{2}$ by ALD thin films, showing that the bulk conductivity of these thin films increases with the degree of reduction. (b) Activation energy $\left(E_{\mathrm{a}}\right)$ as a function of the partial $\mathrm{O}_{2}$ pressure $\left(\mathrm{pO}_{2}\right)$, the blue line corresponds to the $7 \mathrm{meV}$ of ALD deposited $\mathrm{TiO}_{2-x}$. (c) Optical absorptance of $\mathrm{TiO}_{2-x}$ thin films with different $\mathrm{pO}_{2}$ these $\mathrm{TiO}_{2-x}$ films is found to increase with the degree of reduction, showing a broad peak centred around a wavelength of $900 \mathrm{~nm}$, related to the mid-gap optical losses. Following these findings, in devices, the sputtered $\mathrm{TiO}_{2-x}$ reference thin films with $\mathrm{pO}_{2}=7.5 \times 10^{-6}$ mbar were selected for their optimal conductivity-transparency trade-off.

As can be seen in Fig. 4a and b the lowest conductivity and the smallest optical absorptance was obtained with the $\mathrm{TiO}_{2-x}$ by ALD. This would suggest that the ALD $\mathrm{TiO}_{2-x}$ contains a lower level of oxygen vacancies than the sputtered films and hence closer to being stoichiometric. However, previous work has shown that films deposited under these conditions tend to be non-stoichiometric with a significant amount of $\mathrm{Ti}^{3+}$. In addition use of an amine based precursor leads to unintentional doping by carbon and nitrogen within the film. The high level of impurities leads to a reduction in the film conductivity.

Data from the reference cells (Table 4) showed that sputtered thin films of $\mathrm{TiO}_{2-x}$ led to higher $J_{\mathrm{sc}}$ and much lower $R_{\mathrm{oc}}$, hence higher efficiencies for the sputtered over ALD derived samples despite slightly lower transparency. This is consistent with the observed electrical conductivities. However, the same trends in cell properties against FTO thickness were seen for both types of deposition. Data from the cells produced from the APCVD FTO showed that sputtering led to cells with similar efficiencies for both the thinnest and thickest FTO films, although with slightly higher $R_{\mathrm{oc}}$. However, for the intermediate thickness FTO the results were much poorer. This is due to the perovskite layer being less compact due to too fast evaporation of the solvent leaving voids and/or a higher resistance in the ALD layer hindering the extraction of electrons. The latter could be a product of the high temperature $\left(500{ }^{\circ} \mathrm{C}\right)$ scaffold annealing, changing the $\mathrm{TiO}_{2-x}$ structure more adversely for ALD than via sputtering. It is likely on annealing that the thin, amorphous $\mathrm{TiO}_{2-x}$ deposited by ALD crystallises and hence leads to the formation of poor grain boundaries due to the higher level of impurities than those expected in the sputtered film. In addition the annealing could induce cracking of the film.

The much improved uniformity of the FTO and BL aided the formation of a better adhered and uniform perovskite layer. This in turn has allowed us to increase the dimensions of the cells for a batch from $0.43 \mathrm{~cm}^{2}$ to $1 \mathrm{~cm}^{2}$. As can be seen by the cell data for set $\mathrm{D}$ the efficiencies are still as high as, if not higher than that produced for the earlier batches using the smaller cell size. As can be seen in Table 4 as the thickness of the FTO layer is increased there is a corresponding improvement in FF and efficiency, while a decrease in $R_{\mathrm{oc}}$. This can be ascribed to the decrease in FTO sheet resistance, which is demonstrated in Fig. 5 .

The best cell result was obtained from the thickest and hence lowest resistance APCVD FTO layer $\left(7 \Omega \mathrm{sq}^{-1}\right)$, with a sputtered $20 \mathrm{~nm}$ blocking layer with a scaffold and $300 \mathrm{~nm}$ perovskite layer giving an overall value of $16 \%$, which was confirmed by maximum power point (MPP) tracking for 5 minutes. This compares extremely well with literature results for similar cells, Lee et al. ${ }^{16} 16.6 \%$ although with a much smaller cell size of $0.16 \mathrm{~cm}^{2}$ and the certificated value reported by 


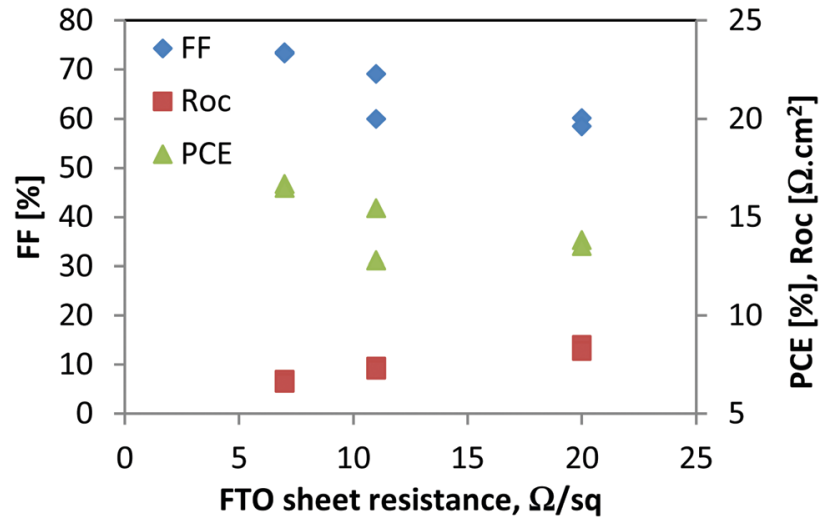

Fig. 5 The trend in cell parameters for FTO set D for the cells fabricated using the sputtered $\mathrm{TiO}_{2-x}$ layer.

Japan's National Institute for Materials Science of 15\%, and similar cell size $1.017 \mathrm{~cm}^{2} .{ }^{34}$ Higher values have been reported by Yang et al. ${ }^{35}$ at $20 \%$ for a $0.096 \mathrm{~cm}^{2}$ cell and Li et al. ${ }^{36} 19.6 \%$ although these are not directly comparable as in the former formamidinium lead triiodide was used and the latter a mixed anion (formamidinium and methylammonium) as well as a mixed halide rather than (in this work) methyl ammonium lead triiodide.

Having achieved this excellent result, further study will be needed to move to planar cells (without the scaffold) as this gives a simpler, cleaner architecture and an easier manufacturing process. For which uniform, highly conformal interfaces will be required to keep a high contact surface area between perovskite and its electron transport layer, while keeping the film pin hole free with low recombination between FTO electrons and perovskite holes.

\section{Conclusions}

We have shown the importance of obtaining uniform thin films of FTO, with low sheet resistance to aid formation of pin hole free uniform $\mathrm{TiO}_{2-x}$ blocking layers and hence well adhered, perovskite layers. It has been confirmed that for cells containing scaffolds the FTO roughness $(<33 \mathrm{~nm})$ is not a major issue. The improved layers' uniformity in turn enabling the formation of large cells $\left(1 \mathrm{~cm}^{2}\right)$ reaching a very high efficiency of $16 \%$.

The optimal BL thickness was $20 \mathrm{~nm}$, while thicker films gave decreased shunt resistance and thinner a greater number of pin holes through the layers. We also showed that the conformal nature of ALD and magnetron sputtering, along with their increased uniformity control over spin coating again improved cell efficiency. The main improvement comes for the smaller $R_{\mathrm{oc}}$, attributed to an improved electrical transport through particularly the sputtered $\mathrm{TiO}_{2-x}$ blocking layer. It is worth noticing that a further improvement could be expected by fine-tuning the stoichiometry of sputtered deposited $\mathrm{TiO}_{2-x}$. Perovskite deposition using a higher concentration and low evaporation rate were crucial to producing dense layers with no gaps into the lower layers of the cell structure.

\section{Acknowledgements}

This work was financed by Framework 7 grant FP7 NMP.2012.1.4-1 309530 PLIANT "Process line implementation for applied surface nanotechnologies".

\section{Notes and references}

1 A. M. Guloy, Nature, 1994, 369, 467-469.

2 A. Krojima, K. Teshima, Y. Shirai and T. Miyasaka, J. Am. Chem. Soc., 2009, 131, 6050-6051.

3 M. M. Lee, J. Teuscher, T. N. Murakami and H. J. Snaith, Science, 2012, 338, 643-647.

4 H.-S. Kim, C.-R. Lee, J.-H. Im, K.-B. Lee, T. Moehl, A. Marchioro, S.-J. Moon, R. Humphry-Baker, J.-H. Yum, J. E. Moser, M. Gratzel and N.-G. Park, Sci. Rep., 2012, 2, 591.

5 D. P. McMeekin, G. Sadoughi, W. Rehman, G. E. Eperon, M. Saliba, M. T. Horantner, A. Haghighirad, N. Sakai, L. Korte, B. Rech, M. B. Johnston, L. M. Herz and H. J. Snaith, Science, 2016, 351, 151-155.

6 W. Chen, Y. Wu, J. Liu, W. Zhang, X. Yang, H. Chen, E. Bi, I. Ashraful, M. Gratzel and L. Hen, Science, 2015, 350, 944-948.

7 J.-W. Lee, D.-J. Seol, A.-N. Cho and N.-G. Park, Adv. Mater., 2014, 26, 4991-4998.

8 M. Saliba, T. Matsui, J.-Y. Seo, K. Domanski, J.-P. CorreaBaena, M. K. Nazeeruddin, S. M. Zakeeruddin, W. Tress, A. Abate, A. Hagfeldt and M. Gratzel, Energy Environ. Sci., 2016, 9, 1989-1997.

9 www.nrel.gov/ncpv/images/efficiency_chart.jpg, accessed 16.08.2016.

10 D. S. Bhachu, D. O. Scanlon, E. J. Saban, H. Bronstein, I. P. Parkin, C. J. Carmalt and R. G. Palgrave, J. Mater. Chem. A, 2015, 3, 9071-9073.

11 S. Chen, J. Briscoe, Y. Shi, K. Chen, R. M. Wilson, S. Dunn and R. Binions, CrystEngComm, 2015, 17, 7486.

12 D. Bi, S.-J. Moon, L. Haggman, G. Boschloo, L. Yang, E. M. Johansson, M. K. Nazeeruddin, M. Gratzel and A. Hagfeldt, RSC Adv., 2013, 3, 18762-18766.

13 M. Anaya, J. F. Galisteo-Lopez, M. E. Calvo, C. Lopez and H. Miguez, J. Phys. Chem. C, 2016, 120, 3071-3076.

14 A. M. A. Leguy, Y. Hu, M. Campoy-Quiles, M. I. Alonso, O. J. Weber, P. Azarhoosh, M. van Schilfgaarde, M. T. Weller, T. Bein, J. Nelson, P. Docampo and P. R. F. Barnes, Chem. Mater., 2015, 27, 3397-3407.

15 W. Tress, N. Marinova, T. Moehl, S. M. Zakeeruddin, M. K. Nazeeruddin and M. Gratzel, Energy Environ. Sci., 2015, 8, 995-1004.

16 Y. H. Lee, J. Luo, R. Humphry-Baker, P. Gao, M. Gratzel and M. K. Nazeeruddin, Adv. Funct. Mater., 2015, 25, 3925-3933.

17 J. Choi, S. Song, M. T. Horantner, H. J. Snaith and T. Park, ACS Nano, 2016, 10, 6029-6036.

18 W. Ke, G. Fang, Q. Liu, L. Xiong, P. Qin, H. Tao, J. Wang, H. Lei, B. Li and J. Wan, J. Am. Chem. Soc., 2015, 137, 6730-6733. 
19 J. T.-W. Wang, J. M. Ball, E. M. Barea, A. Abate, J. A. Alexander-Webber, J. Huang, M. Saliba, I. Mora-Sero, J. Bisquert, H. J. Snaith and R. J. Nicholas, Nano Lett., 2014, 14, 724-730.

20 D. Liu and T. L. Kelly, Nat. Photonics, 2014, 8, 133-138.

21 H. M. Yates, P. Evans, D. W. Sheel, S. Nicolay, L. Ding and C. Ballif, Surf. Coat. Technol., 2013, 230, 228-233.

22 C. Zuo, H. J. Bolink, H. Han, J. Huang, D. Cahen and L. Ding, Adv. Sci., 2016, 3, 1500324.

23 P. Chen, Y. Wang, M. Wang, X. Zhang, L. Wang and Y. Liu, J. Energy Chem., 2015, 24, 717-721.

24 N. Ahn, D.-Y. Son, I.-H. Jang, S. M. Kang, M. Choi and N.G. Park, J. Am. Chem. Soc., 2015, 137, 8696-8699.

25 H. M. Yates, P. Evans, D. W. Sheel, S. Nicolay, L. Ding and C. Ballif, Surf. Coat. Technol., 2012, 213, 167-174.

26 M. H. Siadati and K. K. Chawla, Mater. Charact., 1991, 27, 19-26.

27 M. Afzaal, H. M. Yates and J. L. Hodgkinson, Coatings, 2016, 6, 43-52.
28 S. Faÿ, J. Steinhauser, S. Nicolay and C. Ballif, Thin Solid Films, 2010, 518, 2961-2966.

29 J. Springer, B. Rech, W. Reetz, J. Muller and M. Vanecek, Sol. Energy Mater. Sol. Cells, 2005, 85, 1-11.

30 M. Ritala and M. Leskela, Nanotechnology, 1999, 10, 19-24.

31 Y. W. Chen, J. D. Prange, S. Duhnen, Y. Park, M. Gunji, C. E. D. Chidsey and P. C. McIntyre, Nat. Mater., 2011, 10, 539-544.

32 F. Di Giacomo, V. Zardetto, G. Lucarelli, L. Cinà, A. Di Carlo, M. Creatore and T. M. Brown, Nano Energy, 2016, 30, 460-469.

33 H. M. Yates, P. Evans, D. W. Sheel, U. Dagkaldiran, A. Gordijn, F. Finger, Z. Remes and M. Vanecek, Int. J. Nanotechnol., 2009, 6, 816-827.

34 M. A. Green, K. Emery, Y. Hishikawa, W. Warta and E. D. Dunlop, Prog. Photovoltaics, 2016, 23, 3-11.

35 W. S. Yang, J. H. Yoh, N. J. Jeon, Y. C. Kim, S. Ryu, J. Seo and S. I. Seok, Science, 2015, 348, 1234-1237.

36 X. Li, D. Bi, C. Yi, J.-D. Decoppet, J. Luo, S. M. Zakeeruddin, A. Hagfeldt and M. Gratzel, Science, 2016, 353, 58-62. 